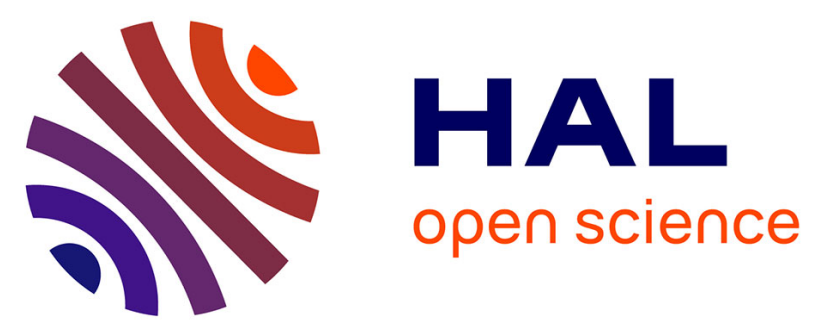

\title{
Mechanistic model to understand in vivo salt release and perception during the consumption of dairy gels
}

Clément de Loubens, Anne Saint-Eve, Isabelle Déléris, Maud Panouillé, Marion Doyennette, Ioan Cristian Tréléa, Isabelle Souchon

\section{- To cite this version:}

Clément de Loubens, Anne Saint-Eve, Isabelle Déléris, Maud Panouillé, Marion Doyennette, et al.. Mechanistic model to understand in vivo salt release and perception during the consumption of dairy gels. Journal of Agricultural and Food Chemistry, 2011, 59 (6), pp.2534-2542. 10.1021/jf103792b . hal-00841596

\section{HAL Id: hal-00841596 https://hal.science/hal-00841596}

Submitted on 8 Jul 2013

HAL is a multi-disciplinary open access archive for the deposit and dissemination of scientific research documents, whether they are published or not. The documents may come from teaching and research institutions in France or abroad, or from public or private research centers.
L'archive ouverte pluridisciplinaire HAL, est destinée au dépôt et à la diffusion de documents scientifiques de niveau recherche, publiés ou non, émanant des établissements d'enseignement et de recherche français ou étrangers, des laboratoires publics ou privés. 


\title{
Mechanistic model to understand in vivo salt
}

\section{release and perception during the consumption}

\section{of dairy gels}

\author{
Clément de Loubens, ${ }^{*},+\ddagger$ Anne Saint-Eve, ${ }^{\dagger, \dagger}$ Isabelle Déléris, ${ }^{\dagger, \ddagger}$ Maud \\ Panouillé, ${ }^{\ddagger}, \dagger$ Marion Doyennette, ${ }^{\dagger, \ddagger}$ Ioan Cristian Tréléa,,$+\dagger$ and Isabelle
} Souchon ${ }^{\dagger, \ddagger}$

INRA, UMR 782 Génie et Microbiologie des Procédés Alimentaires, CBAI 78850

Thiverval Grignon, France, and AgroParisTech, UMR 782 Génie et Microbiologie des Procédés Alimentaires, CBAI 78850 Thiverval Grignon,France

E-mail: cdeloubens@grignon.inra.fr

\begin{abstract}
The objective of this study was to develop a model to simulate salt release during eating. Salt release kinetics during eating were measured for four model dairy products with different dynamic salty perceptions. A simple in vivo model of salt release was developed to differentiate between the contribution of the individual and of the product to salt release. The most difficult model parameter to determine or predict is the evolution of the contact area between the product and the saliva. Fitting the model to the experimental data allowed us to show that the subject's masticatory performance and product structure determined the contact
\end{abstract}

\footnotetext{
${ }^{*}$ To whom correspondence should be addressed

${ }^{\dagger}$ INRA, UMR 782 Génie et Microbiologie des Procédés Alimentaires, CBAI 78850 Thiverval Grignon, France

¥AgroParisTech, UMR 782 Génie et Microbiologie des Procédés Alimentaires, CBAI 78850 Thiverval Grignon,France
} 
area between the product and the saliva generated by mastication. Finally, the role of release dynamics on sensory time-intensity profiles is discussed.

Keywords: mechanistic, cheese, temporal, sensory, $\mathrm{NaCl}$

\section{Introduction}

Reducing salt content in food is a major concern for public health authorities worldwide and a major challenge since it often induces a reduction in sensory quality and technological properties of food products concerning their functionality and their safety. Understanding the mechanisms involved in perception could help to formulate products that satisfy both nutritional and sensory criteria.

During food consumption, salt must be released from the product and diluted in the saliva to reach the taste receptors located on the tongue and, thus, induce salty perception. Understanding and modeling taste compound release during the mastication of "solid" foods is a challenging task due to the complexity of the phenomena that occur in the mouth: dilution by saliva, mastication, temperature modification, etc.

Few studies have attempted to measure the in vivo salt release kinetics during the mastication. Jack et al. (1), Davidson et al. (2) and Neyraud et al. (3) monitored conductivity during eating with electrodes placed in the interdental space between the incisors. However, conductivity probes placed in the mouth can disturb normal mastication behaviour. A non-invasive technique consisted in sampling saliva from the tongue at different moments during the eating process in order to analyse the components present in the saliva $(3-5)$.

Most of the descriptors (initial slope, maximal concentration, etc.) extracted from these kinetics can be statistically related to a subject's physiological parameters such as saliva flow rates or masticatory performance, as well as to product composition (4, 5). However, these statistical approaches are global and do not offer the possibility to understand the contribution of the product and the individual to stimuli release. Modeling was shown to be an effective tool for understanding, quantifying and predicting 
the influence of each parameter on release kinetics.

The first model of flavour release during the consumption of solid products was developed by Harrisson et al. (6). The transport of aroma compounds across the food-saliva interface was described by the interfacial theory of mass transfer. Saliva flow, mastication and swallowing were incorporated into the model. Mastication was modeled by selection and breakage functions to generate particle size distributions but was independent of physiological parameters $(6)$. Wright and Hills $(7,8)$ calculated function parameters from the individual's mastication pattern that was acquired with electromyography and spit out experiments. Detailed knowledge of the mastication process is important to predict particule size distribution and, consequently, the contact area between the product and the saliva and the product and the air (6-8). Food fragmentation can be modeled from empirical laws fitted to experimental data obtained from spit-out experiments $(9,10)$ or by statistical models that consider mastication as a selection and breakdown process $(6,7,11,12)$. Another approach was developed by de Loubens et al. (13). In their study, salt release kinetics were measured after compression of model dairy products. The salt release kinetics from fragmented products were modeled. To model salt release during mastication $(<40 \mathrm{~s})$, they show that knowledge of the size distribution of the particles is unnecessary. The main parameter that has to be known is the evolution of the contact area between the particles and the saliva. These considerations considerably simplify the physical formulation of the model and reduce the number of variables that are often difficult to experimentally determine. The main difficulty in predicting the contact area is due to the fact that it depends a priori on the subject's masticatory behaviour and on the fracture mechanics and reagglomeration of food, which depends on food structure and composition.

The objective of the present study was to develop a model of salt release during the consumption of gel food products and to determine the influence of the product and physiological parameters on the evolution of the product/saliva contact area on the basis of experimental in vivo salt release kinetics.

Firstly, four model dairy products with different compositions were chosen because 
they had already been extensively characterised in terms of rheology and texture (14), as well as in terms of bolus formation (15) and breakdown properties (13). In this study, their sensory dynamic characteristics were determined. An experimental method was used to measure salt release kinetics during eating. The panellists were characterised on a physiological basis. A simple model of salt release was then developed based on the main assumption that generation of the contact area between the product and the saliva governs salt release. This assumption has already been validated by de Loubens et al. (13). On the basis of the experimental data and the model, the specific contributions of the product and of the panellist to this parameter were studied and related to experimentally measurable parameters. Finally, the role of release dynamics on sensory time-intensity profiles is discussed.

\section{Materials \& Methods}

\subsection{Sample preparation}

Model dairy products were prepared as described by Sain-Eve et al. (16): ultra-filtrated skim milk retentate powder PL60 (Triballat, Noyal-sur-Vilaine, France), anhydrous milk fat (Corman, Goe, Belgium) and sodium chloride (Prolabo, France) were mixed and gelled by addition of rennet. Four model cheeses (Table 1) were studied in the present work, varying only in their fat content (0 or 40\%, dry basis) and their retentate powder concentration (150 or $250 \mathrm{~g} / \mathrm{kg}$ ). The other composition parameters remained constant: salt content $(1 \% \mathrm{w} / \mathrm{w})$ and $\mathrm{pH}$-value (6.2). Throughout the paper, products will be referred to according to the following code: PL 60 concentration (150 or $250 \mathrm{~g} / \mathrm{kg}$ ) / fat content (0 or $40 \%)$.

These products had already been extensively characterised in terms of mechanical properties by (14). Figure 1 shows a typical stress-strain curve obtained during product compression (experiments carried out in (14)). For all the products, this curve presented a maximum that corresponds to the fracture initiation. In this study, we calculated two parameters: (i) breakdown energy $E_{b}\left(\right.$ in $k J / m^{3}$ ) defined as the energy necessary to break 
up the product at $80 \%$ of strain and (ii) fracture initiation energy $E_{f i}$ (in $k J / m^{3}$ ) defined as the energy necessary to initiate the fracture in the product.

\subsection{Sensory analysis}

Sixteen volunteer panellists were recruited and trained for the evaluation of salty perception and for time-intensity (TI) methodology. The four training sessions were focused on salty perception in water and in model cheeses (identification, ranking, intensity evaluation and temporal perception), and on software training (using Fizz software). During the product evaluation, the four products were tested in a session and two replicates for the session were performed. The samples were presented monadically. The presentation orders of the products were defined using an orthogonal Latin square. The samples were coded with three-digit random numbers and $5 \mathrm{~g}$ of sample was served at $15^{\circ} \mathrm{C}$. Panelists were asked to rinse their mouth with water and to eat a piece of apple between each sample. The tests were run under white light conditions. For each evaluation, the panellists clicked on the left extremity of a horizontal unstructured scale (corresponding to no sensation) when they put the product into their mouth. Panellists were then asked to move the cursor along the scale as the sensation evolved until the end of the perception.

For each sample, average TI curves were drawn by averaging the data at each time across the 16 subjects and the two replicates. No specific averaging method was used.

\subsection{Physiological measurements}

\section{Masticatory performance}

The masticatory performance $M_{s} P$ of each subject was measured. Each subject was instructed to chew standardised cylinders (weight: $3 \mathrm{~g}$; heigth: $1.8 \mathrm{~cm}$; diameter: $1.4 \mathrm{~cm}$ ) of Optosil silicone dental (Perrigot et Cie, Dijon, France) during 20 masticatory cycles. They were then asked to spit the sample onto a filter paper. The pieces of the chewed sample were spread on paper and dried in an oven for $1 \mathrm{~h}$ at $75^{\circ} \mathrm{C}$. The particles were then separated using a sieve with a 4-mm mesh. The masticatory performance of each 
subject over $20 \mathrm{~s}$ was defined as the amount of sample that passed through the sieve over the amount of chewed sample. This procedure was repeated three times.

\section{Stimulated saliva flow rate}

Stimulated saliva flow rates $Q_{s}$ were measured for each panelist. Panelists chewed $0.5 \mathrm{~g}$ of parafilm (American National Can, Menasha, WI, USA) without swallowing and spit out their saliva at 30 and $60 \mathrm{~s}$. The saliva flow rate is obtained by dividing the mass of saliva collected by the time of the experiment.

\subsection{Experimental measurement of salt release kinetics during eating}

\section{Saliva sampling}

Eight panellists were recruited for this study. Before the product was consumed, the saliva was stimulated with parafilm. Saliva sampling during the consumption of $5 \mathrm{~g}$ of product consisted in the application of a Whatman filter paper for 1-2 seconds on the tongue surface. A first sampling was done at time $t=0$ before product introduction into

the mouth. A second sampling took place just after the time of the first swallowing event $t_{s}$ and the four others at $t_{s}+10 \mathrm{~s}, 40,60$ and $80 \mathrm{~s}$ (from $t_{2}$ to $t_{5}$ ). Before each sampling, panelists were instructed to swallow and to clear their tongue with their teeth. Each piece of filter paper was weighed before and after sampling in order to determine the quantity of saliva sampled. Four replicates per product and per panelist were performed.

\section{Measurement of salt concentration in saliva}

Salt concentration in saliva was measured with a conductivity probe (Heito, France) that was calibrated at $20^{\circ} \mathrm{C}$ with aqueous $\mathrm{NaCl}$ solutions prepared with deionised water. In the present work, the concentrations are given in equivalent $\mathrm{g} / \mathrm{L}$ of $\mathrm{NaCl}$.

In addition to $\mathrm{NaCl}$, model cheeses contained other solutes such as potassium, calcium, phosphates, citrates and lactates (17). Moreover, saliva contains naturally different 
solutes (3) whose concentrations differ depending on whether the saliva is stimulated or not. This is the reason why saliva was stimulated with parafilm before product consumption and its conductivity was measured just before eating to take this value into account. In the present paper, we defined "salt" as all the species that contribute to the conductivity signal.

The piece of filter paper used for saliva sampling was placed and shaken in $15 \mathrm{~mL}$ of deionised water during $15 \mathrm{~min}$ at $20^{\circ} \mathrm{C}$. The conductivity of the solution was measured. Given the dilution rate, the conductivity of the saliva sample was determined. The filter paper contribution to the conductivity signal was measured beforehand and subtracted from the global signal.

\subsection{Mathematical model}

\subsubsection{Hypothesis of the developed model}

Mass transfer theory During mastication, the product is fractionated into little pieces and its contact area with saliva increases. To model flavour release from a chewed bolus, Harrison et al. and Wright and Hills $(6-8)$ calculated the particle size distribution generated by mastication. Modeling the particle size distribution is of minor interest except to calculate the contact area. In fact considering that the mastication time $(\sim 10 \mathrm{~s}$ in the experiments) is relatively short compared to the characteristic time of release, the size distribution is expected to have a low impact on the kinetics. For example, considering that salt release is due to a Fickian diffusion $\left(D \sim 10^{-9}-10^{-10} m^{2} / s,(14,18)\right)$,

the product thickness where the concentration significantly decreases is given by $\sqrt{4 D t}$ (18) and, consequently, is approximately 0.06-0.2 mm. Considering a melting surface phenomenon, the thickness is given by $t v$ where $v$ is the velocity of the surface layer melting $\left(v \sim 3.10^{-5} \mathrm{~m} / \mathrm{s},(8)\right)$ that is approximately $0.3 \mathrm{~mm}$. This thickness range is relatively small compared to the median particle size measured just before swallowing, which is approximately $2.8 \mathrm{~mm}$ for carrots and $1 \mathrm{~mm}$ for peanuts $(19,20)$. Therefore, the salt concentration in the bulk product has not yet the time to significantly decrease and remains homogeneous. Hence, the time of mastication is sufficiently short to not 
take the particle size distribution into account. Knowledge of the saliva/product contact area is sufficient to satisfactorily represent the mass transfer phenomena and to consider that the concentration in solutes inside the product is homogeneous. These considerations considerably simplify the mastication model formulation and reduce the number of variables required for the model that are often difficult to determine experimentally. Finally, as shown in Figure 2, we can assume that the release of solutes can be described by a mass transfer coefficient $k_{p}(\mathrm{~m} / \mathrm{s})$ and that salt concentration in the bulk product $C_{p}$ can be considered uniform during the short residence time of the product in the mouth. For short times $(<40 \mathrm{~s})$, this type of model has already been successfully validated on salt release kinetics from the same dairy gels reduced into small particles by standardised compression (13).

\section{Evolution of the contact area between product and saliva and of the volume of}

saliva Bolus volume increases with the saliva flow rate. At each swallowing event, part of the product and of the saliva transit to the pharynx. Hence, product and saliva volumes and contact area instantly decrease. Between two swallows, saliva volume increases linearly with the saliva flow rate. The variations of contact area $A(t)$ and of saliva volume $V_{s}(t)$ are shown on Figure 2-b and c. The initial area $A_{0}$ is given by the initial geometry of the sample. We consider that before the first swallowing event, the evolution of the contact area between product and saliva is linear. Firstly, the products being fragmented during the course of the mastication, its contact area with saliva increases. Secondly, assuming a linear increase is the simplest assumption that does not overparameterize the model according to the experimental data. It is assumed that the contact area at the swallowing time $A_{\max }$ depends on the product and on the panellist. Formally, this can be written as the product of two functions:

$$
A_{\text {max }}=F(\text { product }) \times G(\text { panellist })
$$

where $F$ and $G$ are two functions that depend on the product and on the panelist respectively 
We observed experimentally that very few product remained in mouth after the first swallowing event $t_{s}$. Thus, the contact area and the product volume in the mouth are considered to be null.

\subsubsection{Mathematical model formulation}

The evolution of salt concentration in saliva $C_{s}$ over time $t$ is given by a mass balance between product and saliva and takes the dilution by the saliva flow rate $Q_{s}$ into account (Figure 2-a). The salt concentration in the inlet saliva is referred to as $C_{Q}$ :

$$
V_{s}(t) \frac{d C_{s}}{d t}=k_{p} A(t)\left(K . C_{p}(t)-C_{s}(t)\right)+Q_{s}\left(C_{Q}(t)-C_{s}(t)\right)
$$

where $K=C_{s}^{e q} / C_{p}^{e q}$ is the saliva/product partition coefficient and $k_{p}$ the mass transfer coefficient $(\mathrm{m} / \mathrm{s})$. The remaining salt concentration in the product is:

$$
V_{p} \frac{d C_{p}}{d t}=-k_{p} A(t)\left(K . C_{p}(t)-C_{s}(t)\right)
$$

where $V_{p}$ is the volume of product $\left(\mathrm{m}^{3}\right)$. As previously explained, the contact area is given by (Figure 2):

$$
A(t)=\left\{\begin{array}{c}
A_{0}+\left(A_{\max }-A_{0}\right) \frac{t}{t_{s}} \text { if } t<t_{s} \\
0 \text { else }
\end{array}\right.
$$

where $A_{\max }$ is defined by (Eq. (1)).

Considering that saliva volume $V_{s}$ decreases to its initial value at each swallowing (Figure 2), we have:

$$
V_{s}(t)=\left\{\begin{array}{c}
V_{s 0}+Q_{s} t \text { if } t<t_{s} \\
V_{s 0}+Q_{s}\left(t-t_{s}\right) \text { if } t_{s}<t<t_{i} \\
\cdots
\end{array}\right.
$$

where $t_{i}(i \in \overline{2 . .5})$ are the times of the different swallowing events (Figure 2)

The initial conditions are: 


$$
\begin{gathered}
C_{s}(t=0)=C_{Q} \\
C_{p}(t=0)=C_{p 0}
\end{gathered}
$$

\subsubsection{Inverse method for determining unknown model parameters}

This equation system was solved with Matlab 7 (The Mathworks, Natick, MA, USA). Model parameters are summed up in Table 2. The value of $K, k_{p}$ and $C_{p 0}$ were fixed and were those obtained by de Loubens et al. (13) for the same products. Partition coefficients $K$ were comprised between 0.7 and 1 , mass transfer coefficients $k_{p}$ ranged between 2 and $3.10^{-6} \mathrm{~m} / \mathrm{s}$ and initial salt concentration in the products $C_{p 0}$ were between

$13 \mathrm{~g} / \mathrm{L}$ and $17 \mathrm{~g} / \mathrm{L}$. Saliva flow rate $Q_{s}$ was measured experimentally for each panelist. For each data set, salt concentration in inlet saliva $C_{Q}$ was given by the concentration at the first point of the kinetics $(t=0)$, which is the salt concentration in stimulated saliva. Three model parameters were unknown beforehand: the two functions $F$ and $G$ and the initial saliva volume $V_{s 0}$ which was assumed to be dependent on the panellist alone.

In a first step, fitting the model to all experimental data from the swallowing events (from $t=t_{s}$ to $t=t_{5}$ ) made it possible to determine the initial volume of saliva $V_{s 0}$ for each panellist. In fact, the concentration measured at the first swallow $\left(t=t_{s}\right)$ is considered as an initial condition, the equation system is reduced to Eq. (2) and Eq. (5) where $A=0$ and is therefore independent of $F$ and $G$.

In a second step, given $V_{s 0}$, functions $F$ (product) and $G$ (panellist) were determined by fitting the model to the two first experimental points (from $t=0$ to $t=t_{s}$ ) for all data. Since $F$ and $G$ are defined up to a common multiplicative factor, it is necessary to fix the value of one of these functions for a panellist or a product. We initially set $F(250 / 40)=1$. 


\section{Results \& Discussion}

\subsection{Impact of product on salty perception}

The differences in perception of the studied dairy gels were previously highlighted by a profile method (14) and a temporal dominance of sensations method (13), which revealed, in particular, a strong effect of fat content and a weaker effect of dry matter content on salty perception, and a high product effect on the dynamics of dominance of salty and texture perception. Subsequent to this result, it seems important to study the dynamics of salty perception in order to identify and quantify the salt release mechanisms at the origin of perception using an experimental and modeling approach.

Figure 3 represents the time intensity profile averaged for each product and all panellists.A one-way ANOVA with product as factor was performed in order to analyse which time-intensity parameters that showed significant differences. The area under the curve (AUC) and the maximum intensity (Imax) were statistically influenced by the structure and composition of the products $(\mathrm{p}<0.0001)$. The maximum perceived intensity of the salty taste is significantly increased by fat addition for products with low dry matter. Moreover, when fat was present in the product, the maximum perceived intensity occured later, contrary to low-fat products.

\subsection{Physiological parameters}

The values of the physiological parameters used in the model are given Table 2 . The experimental stimulated salivary flow rates $Q_{s}$ were between 0.6 and $3.6 \mathrm{~mL} / \mathrm{min}$. The saliva volume $V_{s 0}$ obtained by fitting the model to the experimental data was between 0.3 and $2.5 \mathrm{~mL}$. The salt concentration in stimulated saliva $C_{Q}$ was approximately $1.3 \mathrm{~g} / \mathrm{L}$ eq. $\mathrm{NaCl}$. These data were in agreement with those in the literature (3, 21-23).

\subsection{Product and subject influences on salt release kinetics}

Figure 4 shows typical evolutions of salt concentration in the mouth during the consumption of model dairy products for one panelist. For each piece of data, the associated error 
bars show the minimum and maximum of the four replicates and are relatively small. Regardless of the product or the panelist, the kinetics had similar profiles. Between the time at which the product was put in the mouth and the first swallowing event, salt concentration increased due to the salt release from product to saliva. After the first swallowing event, the concentration decreased because the saliva remaining in the mouth was diluted by the saliva flow rate from the salivary glands, moreover the product was swallowed. The maximal concentrations of salt measured at the first swallowing event ranged from 8 to $13 \mathrm{~g} / \mathrm{L}$. This value can be compared to the initial salt concentration in the products that are between 15 and $17 \mathrm{~g} / \mathrm{L}$. Thus, at the first swallowing event, the solute distribution between the product and the saliva was relatively close to the equilibrium, implying that the maximal salt concentration could be reached at the first swallowing event.

Product and subject effects on salt release kinetics were tested statistically. Tests were performed on the following descriptors extracted from the release kinetics: (i) first swallowing time $t_{s}$, (ii) concentration at the first swallow $C_{s}\left(t_{s}\right)$ normalised by the initial concentration of solutes in the product $C_{p 0}$ and the partition coefficient $K$ (i.e., $\left.C_{s}\left(t_{s}\right) / K C_{p 0}\right)$ and (iii) characteristic time of the decreasing part of the kinetics $\tau$ (determined by fitting an exponential law on this part of the kinetics).

The first swallowing time ranged from 8 to $22 \mathrm{~s}$. This parameter was influenced by product and subject, and a product-subject interaction was observed $\left(p<10^{-4}\right)$. The swallowing time was correlated with the breakdown energy $E_{b}$ that describes mechanical properties of the product under large deformation $\left(R^{2}=0.95\right.$, Figure 5$)$.

The normalised concentration at the first swallowing time was influenced by product and subject, and a product-subject interaction was observed $\left(p<10^{-4}\right)$. The product 250/40 was significantly different from 150/40 (Table 3).

The characteristic time of the decreasing part of the kinetics $\tau$ provided information about the "salt persistence." The longer the $\tau$ is, the longer the solutes remain in the mouth and the more persistent the product is. As in the case of the other parameters, $\tau$ was influenced by the subject, the product and the product-subject interaction. Subject 
influence could be mainly explained by the saliva volume and the salivary flow rate. Products were statistically classified into two groups (Table 3). The first group was composed of 250/40 only and the second one of 250/0, 150/0 and 150/40. Two hypotheses can be formulated to explain this phenomenon: either the saliva flow rate depended on the product or some little pieces of product adhered to the tongue surface and acted as a reservoir for solute release. Further studies are needed to improve our understanding of these phenomena.

In conclusion, product and subject influenced release kinetics and a product-subject interaction was observed. In the model, product influence was represented by the salt physico-chemical properties in the product (mass transfer coefficient $k_{p}$ and partition coefficient $K$ ) and subject influence was represented by its physiological parameters (the initial saliva volume and the salivary flow rate). The product / subject interaction was introduced by considering that the maximal contact surface during the mastication $A_{\max }$ was a function of both the product and the panellist. We assumed that the initial volume of saliva $V_{s 0}$ and the salivary flow rate $Q_{s}$ were product- and time- independent.

\subsection{Modeling salt relase during food consumption}

\section{Model sensitivity analysis}

In this section, the effects of some of the parameters on model predictions are analysed. The values used for the sensitivity analysis were chosen according to the physiological values measured in this study and the physico-chemical parameters measured by de Loubens et al. (13). As shown in Figure 6-a, the product/saliva contact area $A_{\max }$ mainly has an influence on release kinetics before the first swallowing event. The greater the contact area is, the faster the solute release is. When the area is sufficiently large, the salt equilibrium between the saliva and the product is reached before the first swallowing event.

The initial volume of saliva $V_{s 0}$ has an influence on the salt concentration at the first swallowing event and on the decay of salt concentration after this event (Figure 6-b). A small saliva volume induces a high salt concentration in saliva, but the decay of the 
concentration after the first swallowing event is faster. Since the characteristic time of the decay is given by the ratio $V_{s 0} / Q_{s}$, a large saliva volume and a weak saliva flow rate increase the "salt persistence" of the product.

A high saliva flow rate $Q_{s}$ reduces the salt concentration at the first swallowing event and accelerates the decay by diluting salt in saliva (Figure 6-c).

\section{Relationship between the maximal contact area $A_{\max }$, the product and the subject}

In Section 2.5, the maximal product / saliva contact area $A_{\max }$ was assumed to be the product of two functions $F$ and $G$ that depend only on the product and the panellist respectively: $A_{\max }=F($ product $) \times G$ (panellist). This equation allowed us to determine the respective contribution of the product and of the panellist to the dynamics of contact area generation.

After fitting the model to the salt release kinetics as explained in Section 2.5, a good regression between the function $G$ and the masticatory performance $M_{s} P$ was found $\left(R^{2}=0.90\right.$ Figure 7$)$ :

$$
G=\alpha \exp \left(\beta \times M_{s} P\right)
$$

where $\alpha$ and $\beta$ are two constants. Finally, $A_{\max }$ is reduced to a function of $F(F \leftarrow \alpha F)$ and $M_{s} P$ :

$$
A_{\text {max }}=F(\text { product }) \exp \left(\beta \times M_{s} P\right)
$$

Considering that $A_{\max }$ is given by Eq. (2), the values of $F, \beta$ and $V_{s 0}$ previously obtained were used as an initial attempt to fit the model to the complete kinetics (from $t=0$ to $t=t_{5}$, Figure 2) in order to refine the values of $F, \beta$ and $V_{s 0}$. The determination coefficient $R^{2}$ was 0.91 . We determined that $\beta=3.9 \pm 0.2$ and $V_{s 0}$ was between 0.3 and $2.5 \mathrm{~mL}$.

In Figure 8, we can observe that the values of $F$ between each product were close 
compared to the inter-individual variability (Function $G$ ). We compared the value of $F$ with the area generated by a standardised compression under in vitro conditions $A_{c}$, which was determined by de Loubens et al. (13) (Figure 8). This parameter $\left(A_{c}\right)$ is a representation of the breakdown product properties translated in terms of contact area of the product with the surrounding aqueous phase. The product $250 / 40$ had a value of $F$ that was slightly higher than the others products. This difference was more evident after the in vitro compression. In fact, panellists adpat their mastication behaviour according to the product structure (Figure 5): the firmer the product is, the longer the subject chews it before swallowing and the greater the quantity of salt released is. Similar results have already been observed (24-27). Depending on their texture perception, subjects adapted their chewing time to reach the same bolus state. The analysis of the ready-toswallow bolus by image analysis revealed similar results (19): mean particle width and particle size distribution do not depend on the specific food (ex: carrot and radish) but, instead, on the food type (ex: dried nuts and raw vegetables).

Finally, $A_{\max }$ is clearly related to the subject's masticatory performance and is slightly dependent on the breakdown properties of the product.

However, as shown in Figure 9, the dynamics of contact area evolution (represented by the ratio $F$ (product) $\left./ t_{s}\right)$ is very different between the products. $F$ (product) $/ t_{s}$ is very well correlated with the fracture initiation energy $E_{f i}\left(R^{2}=0.94\right) . F($ product $) / t_{s}$ represents the dynamics of evolution of the contact area between the product and the saliva independently of the panelist effect.

\section{Final model adjustment}

Figure 10 shows the salt release kinetics fitted to the experimental data (from $A_{\max }$ defined with Eq. (9)) for two panelists (subjects 4 and 7) and two products varying in fat content (250/40 and 250/0). The comparison of these two panellists is interesting since they had different physiological parameters and different behaviours. In fact their masticatory performance $M_{s} P$ was very different: 0.52 (subject 4) and 0.19 (subject 7). For panelist 4 , the maximal contact area $A_{\max }$ generated with product $250 / 40$ was 
sufficiently large $\left(281 \mathrm{~cm}^{2}\right)$ so as not to limit salt release (Figure 10): the concentrations of salt between the product and the saliva were very close to the equilibrium at the first swallowing event. In contrast, panellist 7's masticatory behaviour did not make it possible to generate a sufficiently large area, regardless of the product $\left(A_{\max }<75 \mathrm{~cm}^{2}\right.$, Figure $10-$ b): the saliva/product equilibrium was never reached at the first swallowing event. The panellist's masticatory performance therefore limited the generation of contact area and salt release. Compared to the inter-individual variability, the differences between the products were relatively low. However, a greater maximal contact area was generated with the fat product $(250 / 40)$ than with the non-fat product. These differences can be explained by a longer mastication time for fat products that are related to the breakdown energy (Figure 5) and by the different breakdown properties between the two products (Figure 8, Figure 9).

Finally, considering that salt release can be described by a mass transfer coefficient and that salt concentration in the bulk product remains homogeneous during the small residence time of the product in the mouth, this simplifies the formulation of the mathematical problem and reduces the number of parameters to be known. These hypotheses have already been successfully validated on in vitro data by de Loubens et al. (13). In fact, only the product volume and the saliva/product contact area need to be known. The evolution of the contact area was assumed to be linear. It could be refined and improved if more detailed experimental data were available, namely during the first seconds of the mastication period. New experimental methodologies must be developed to acquire such data without disturbing the natural mastication behaviour of the panellists.

\section{Salty perception and salt release kinetics}

No direct relationships were observed between the salt release kinetics and the salty intensity of the time-intensity profiles on the basis of data from the present study. For example, the correlation coefficient between the area under the curves of the time-intensity profile and the concentration reached at the first swallowing event is 0.2. Morris et al. (28) suggested that the overall amount of delivered salt affects sensory perception. In 
the present study, the quantity of salt delivered during mastication was calculated using the mechanistic model. The relationships between this parameter and the area under the curves of time-intensity profiles and the maximal intensity are not satisfactory $\left(R^{2}<0.1\right)$.

However, specific studies on sensory receptors assume that receptor response depends on the type of stimulation: the rate of taste molecules transported to the taste receptors can influence the receptor response (29-31). Busch et al. (32) investigated this hypothesis for salt perception on humans. On the basis of salt pulse experiments, they concluded that the frequency, timing and concentration differences of salt stimuli can affect saltiness. For aroma compounds, Baek et al. (33) showed no correlation between the amount of volatile release and the sensory analysis, but found a good correlation between the rates of volatile release and the sensory data. In order to investigate the hypothesis that perception is related to the salt release rate, we simulated the salt release rate with the model developed and the parameters determined in the present study and calculated the maximal slope of the evolution of salt concentration in saliva (i.e., $\max \left(d C_{s} / d t\right)$ ). A better correlation between the maximal salty intensity and the maximal slope of the evolution of salt concentration $\left(R^{2}=0.6\right)$ was observed. This result suggests that salt perception can be partly explained by the rate of salt release. However, this relationship between release and perception needs to be investigated further. Controlled salt delivery experiments should allow us to determine the links or the "transfer function" between release and perception.

To conclude, the model developed in the present study made it possible to better understand the mechanisms of salt release and perception during food consumption with physiological parameters (salivary flow rate and masticatory efficiency) and the rheological and breakdown parameters of food. This type of model could be a good tool to formulate products that satisfy both nutritional and organoleptic criteria. 


\section{Acknowledgments}

The authors gratefully acknowledge the French National Research Agency (ANR) project

SensInMouth for its financial support. We would also like to thank F. Chardin and D. Forest for their technical contributions. 


\section{References}

(1) Jack, F.; Piggott, J.; Paterson, A. Cheddar cheese texture related to salt release during chewing, measured by conductivity - preliminary study. Journal of Food Science 1995, 60, 213-217

(2) Davidson, J.; Linforth, R.; Taylor, A. In-mouth measurement of pH and conductivity during eating. Journal of Agricultural and Food Chemistry 1998, 46, 5210-5214

(3) Neyraud, E.; Prinz, J.; Dransfield, E. NaCl and sugar release, salivation and taste during mastication of salted chewing gum. Physiology and Behavior 2003, 79, 731 $-737$

(4) Pionnier, E.; Chabanet, C.; Mioche, L.; Taylor, A.; Le Quere, J.; Salles, C. 2. In vivo nonvolatile release during eating of a model cheese: Relationships with oral parameters. Journal of Agricultural and Food Chemistry 2004, 52, 565-571

(5) Phan, V.; Yven, C.; Lawrence, G.; Chabanet, C.; Reparet, J.; Salles, C. In vivo sodium release related to salty perception during eating model cheeses of different textures. International Dairy Journal 2008, 18, 956 - 963

(6) Harrison, M.; Campbell, S.; Hills, B. Computer simulation of flavor release from solid foods in the mouth. Journal of Agricultural and Food Chemistry 1998, 46, $2736-2743$

(7) Wright, K.; Sprunt, J.; Smith, A.; Hills, B. Modelling flavour release from a chewed bolus in the mouth: Part I. Mastication. International Journal of Food Science and Technology 2003, 38, 351-360 
(8) Wright, K.; Hills, B. Modelling flavour release from a chewed bolus in the mouth: Part II. The release kinetics. International Journal of Food Science and Technology 2003, 38, 361-368

(9) Kobayashi, N.; Kohyama, K.; Sasaki, Y.; Matsushita, M. Statistical laws for food fragmentation by human mastication. Journal of the Physical Society of Japan 2006, 75,083001

(10) Kobayashi, N.; Kohyama, K.; Shiozawa, K. Fragmentation of a Viscoelastic Food by Human Mastication. Journal of the Physical Society of Japan 2010, 79, 044801.

(11) van der Bilt, A.; Olthoff, L.; van der Glas, H.; van der Weelen, K.; Bosman, F. A mathematical description of the comminution of food during mastication in man. Archives of Oral Biology 1987, 32, $579-586$

(12) Baragar, F.; van der Bilt, A.; van der Glas, H. An analytic probability density for particle size in human mastication. Journal of Theoretical Biology 1996, 181, $169-178$

(13) de Loubens, C.; Panouillé, M.; Saint-Eve, E.; Déléris, I.; Tréléa, I.C.; Souchon, I. Mechanistic model of in vitro salt release from model dairy gels based on standardized breakdown test simulating mastication. Journal of Food Engineering accepted

(14) Panouillé, M.; Saint-Eve, A.; de Loubens, C.; Déléris, I.; Souchon, I. Understanding of the influence of composition, structure and texture influence on salty perception in model dairy products. Food Hydrocolloids 2010 doi:10.1016/j.foodhyd.2010.08.021 
(15) Drago, S.; Panouillé, M.; Saint-Eve, A.; Neyraud, E.; Feron, G.; Souchon, I. Relationships between saliva and food bolus properties from model dairy products. Food Hydrocolloids 2010 doi:10.1016/j.foodhyd.2010.0\%.024

(16) Saint-Eve, A.; Lauverjat, C.; Magnan, C.; Déléris, I.; Souchon, I. Reducing salt and fat content: Impact of composition, texture and cognitive interactions on the perception of flavoured model cheeses. Food Chemistry 2009, 116, 167-175

(17) Floury, J.; Rouaud, O.; Poullennec, M. L.; Famelart, M.-H. Reducing salt level in food: Part 2. Modelling salt diffusion in model cheese systems with regards to their composition. LWT - Food Science and Technology 2009, 42, 1621 - 1628

(18) Cussler, E. Diffusion. Mass Transfer in Fluid Systems. 2nd edition; University Press, Cambridge, 1997

(19) Mishellany, A.; Woda, A.; Labas, R.; Peyron, M.-A. The challenge of mastication: Preparing a bolus suitable for deglutition. Dysphagia 2006, 21, 87-94

(20) Woda, A.; Nicolas, E.; Mishellany-Dutour, A.; Hennequin, M.; Mazille, M. N.; Veyrune, J. L.; Peyron, M. A. The Masticatory Normative Indicator. Journal of Dental Research 2010, 89, 281-285

(21) Pionnier, E.; Chabanet, C.; Mioche, L.; Le Quere, J.; Salles, C. 1. In vivo aroma release during eating of a model cheese: Relationships with oral parameters. Journal of Agricultural and Food Chemistry 2004, 52, 557-564 
(22) Dawes, C. Salivary flow patterns and the health of hard and soft oral tissues. Journal of the American Dental Association 2008, 139, 18S-24S

(23) Muller, K.; Figueroa, C.; Martinez, C.; Medel, M.; Obreque, E.; Pena-Neira, A.; Morales-Bozo, I.; Toledo, H.; Lopez-Solis, R. O. Measurement of saliva volume in the mouth of members of a trained sensory panel using a beetroot (Beta vulgaris) extract. Food Quality and Preference 2010, 21, 569 - 574

(24) Boland, A.; Delahunty, C.; van Ruth, S. Influence of the texture of gelatin gels and pectin gels on strawberry flavour release and perception. Food Chemistry 2006, 96, $452-460$.

(25) Gierczynski, I.; Laboure, H.; Semon, E.; Guichard, E. Impact of hardness of model fresh cheese on aroma release: In vivo and in vitro study. Journal of Agricultural and Food Chemistry 2007, 55, 3066-3073

(26) van Ruth, S.; Buhr, K. Influence of mastication rate on dynamic flavour release analysed by combined model mouth/proton transfer reaction-mass spectrometry. International Journal of Mass Spectrometry 2004, 239, 187-192,

(27) Lauverjat, C.; Déléris, I.; Tréléa, I. C.; Salles, C.; Souchon, I. Salt and aroma compound release in model cheeses in relation to their mobility. Journal of Agricultural and Food Chemistry 2009, 5\%, 9878-9887

(28) Morris, C.; Koliandris, A.-L.; Wolf, B.; Hort, J.; Taylor, A. J. Effect of Pulsed or Continuous Delivery of Salt on Sensory Perception Over Short Time Intervals. Chemosensory Perception 2009, 2, 1-8 
(29) Meiselman, H. L.; Bose, H. E.; Nykvist, W. E. Effect of flow rate on taste intensity responses in humans. Physiology \& Behavior 1972, 9, $35-38$.

(30) Halpern, B. P.; Kelling, S. T.; Meiselman, H. L. An analysis of the role of stimulus removal in taste adaptation by means of simulated drinking. Physiology $\&$ Behavior 1986, 36, $925-928$

(31) Alberts, B.; Lewis, J.; Raff, M.; Roberts, K.; JD, W. Cell signalling; New-York: Garland Publishing Inc, 1994; pp 721-785

(32) Busch, J. L. H. C.; Tournier, C.; Knoop, J. E.; Kooyman, G.; Smit, G. Temporal Contrast of Salt Delivery in Mouth Increases Salt Perception. Chemical Senses 2009, $34,341-348$

(33) Baek, I.; Linforth, R.; Blake, A.; Taylor, A. Sensory perception is related to the rate of change of volatile concentration in-nose during eating of model gels. Chemical Senses 1999, 24, 155-160. 


\section{List of Tables}

1 Composition and codes of model dairy products. . . . . . . . . . 25

2 Model parameters: mean values and standard deviation (SD) . . . . . 25

3 Normalized concentration $C_{s}\left(t_{s}\right) / K C_{m 0}$ at the first swallowing and mean characteristic time $\tau$ of the decreasing part of release kinetics for the different products with confidence intervals. The products are statistically classified in two groups referred to as a and b (SNK Test). . . . . . . . . 25 
Table 1: Composition and codes of model dairy products.

\begin{tabular}{lcccc} 
& $250 / 40$ & $250 / 0$ & $150 / 40$ & $150 / 0$ \\
\hline Milk retentate powder $[\mathrm{g} / \mathrm{kg}]$ & 250 & 250 & 150 & 150 \\
Anhydrous milk fat $[\mathrm{g} / 100 \mathrm{~g} \mathrm{DM}]$ & 40 & 0 & 40 & 0 \\
Water $[\mathrm{g} / \mathrm{kg}]$ & 573 & 740 & 740 & 850 \\
\hline
\end{tabular}

Table 2: Model parameters: mean values and standard deviation (SD)

\begin{tabular}{lcccc}
\hline Model parameters & Unit & Symbol & Mean \pm SD & References \\
\hline Saliva flow rate & {$[\mathrm{mL} / \mathrm{min}]$} & $Q_{s}$ & $2.2 \pm 0.9$ & $1.7 \pm 0.6(3)$ \\
& & & & $1.2 \pm 0.8(21)$ \\
& & & & $1.5 \pm 0.5(22)$ \\
\hline Volume of saliva & {$[\mathrm{mL}]$} & $V_{s 0}$ & $1.1 \pm 0.6$ & $0.7 \pm 0.3(23)$ \\
\hline Salt concentration in stimulated saliva & {$[\mathrm{g} / \mathrm{L}$ eq. $\mathrm{NaCl}]$} & $C_{Q}$ & $1.3 \pm 0.6$ & $2.5 \pm 1.2(3)$ \\
\hline Salt partition coefficient product / saliva & {$[-]$} & $K$ & $0.85 \pm 0.15$ & $0.75 \pm 0.15(27)$ \\
\hline Mass tranfer coefficient & {$\left[\mathrm{x} 10^{-6} \mathrm{~m} / \mathrm{s}\right]$} & $k_{p}$ & $2.2 \pm 0.3$ & \\
\hline
\end{tabular}

Table 3: Normalized concentration $C_{s}\left(t_{s}\right) / K C_{m 0}$ at the first swallowing and mean characteristic time $\tau$ of the decreasing part of release kinetics for the different products with confidence intervals. The products are statistically classified in two groups referred to as $\mathrm{a}$ and $\mathrm{b}$ (SNK Test).

\begin{tabular}{lcc} 
& $\begin{array}{c}\text { Normalized concentration } \\
C_{s}\left(t_{s}\right) / K C_{m 0}[-]\end{array}$ & $\begin{array}{c}\text { Characteristic time of the decay } \\
\tau[\mathrm{s}]\end{array}$ \\
\hline $250 / 40$ & $0.77 \pm 0.04(\mathrm{a})$ & $56 \pm 14(\mathrm{a})$ \\
$250 / 0$ & $0.71 \pm 0.04(\mathrm{a}, \mathrm{b})$ & $45 \pm 11(\mathrm{~b})$ \\
$150 / 40$ & $0.63 \pm 0.03(\mathrm{~b})$ & $43 \pm 8(\mathrm{~b})$ \\
$150 / 0$ & $0.70 \pm 0.05(\mathrm{a}, \mathrm{b})$ & $45 \pm 12(\mathrm{~b})$ \\
\hline
\end{tabular}




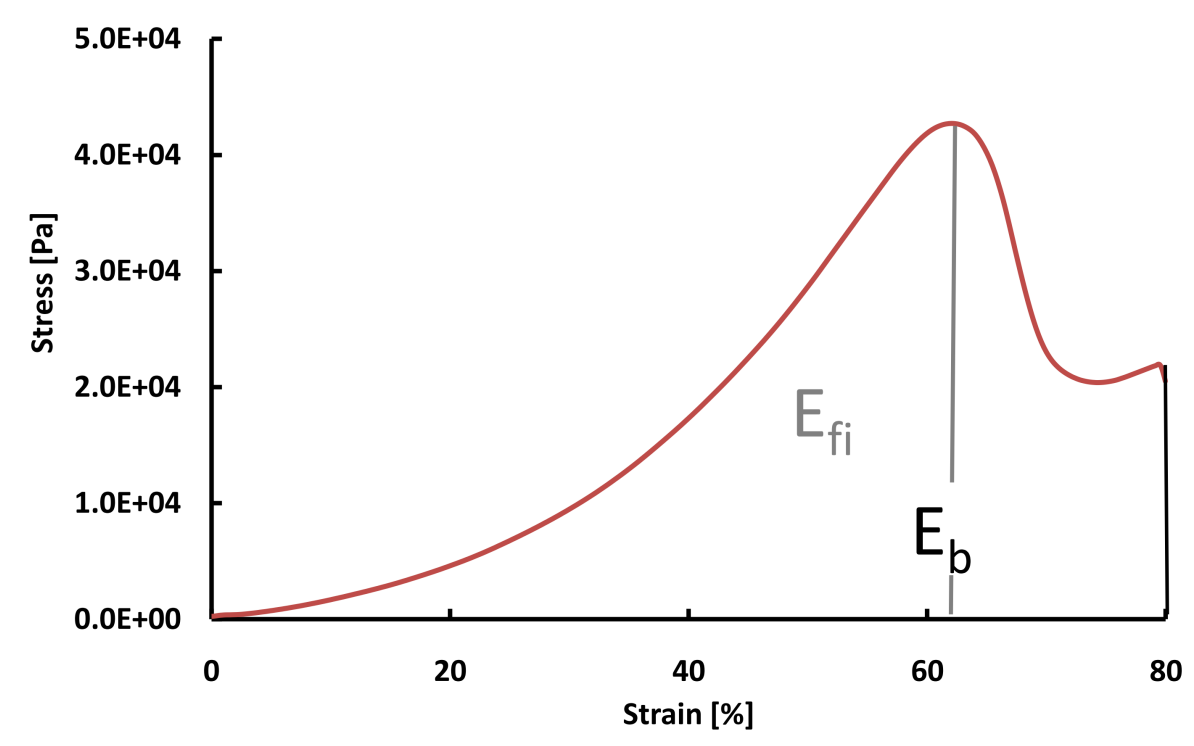

Figure 1: Typical stress-strain curve during product compression. The maximum of the curve represents fracture initiation. Breakdown energy $E_{b}$ is defined as being the energy necessary to break up the product at $80 \%$ of strain (i.e total area under the curve). Fracture initiation energy $E_{f i}$ is defined as being the energy necessary to initiate the fracture in the product. These data were calculated from the experiments carried out in (14). 

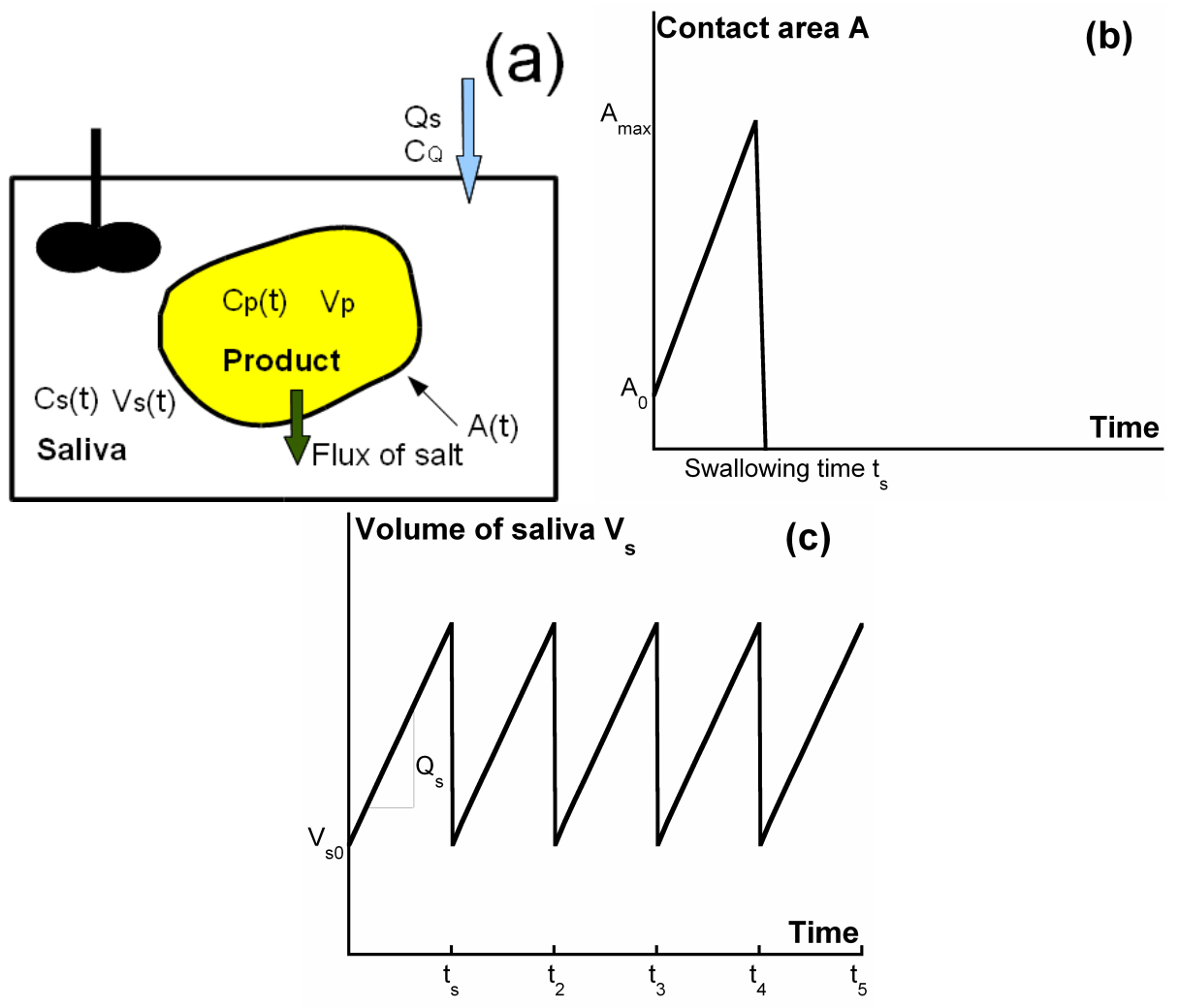

Figure 2: Model assumptions: (a) principles and notations of the in-mouth salt release model during eating; (b) hypothesis of the change of the contact area between the product and the saliva during eating; (c) hypothesis of evolution of saliva volume in mouth during eating. 


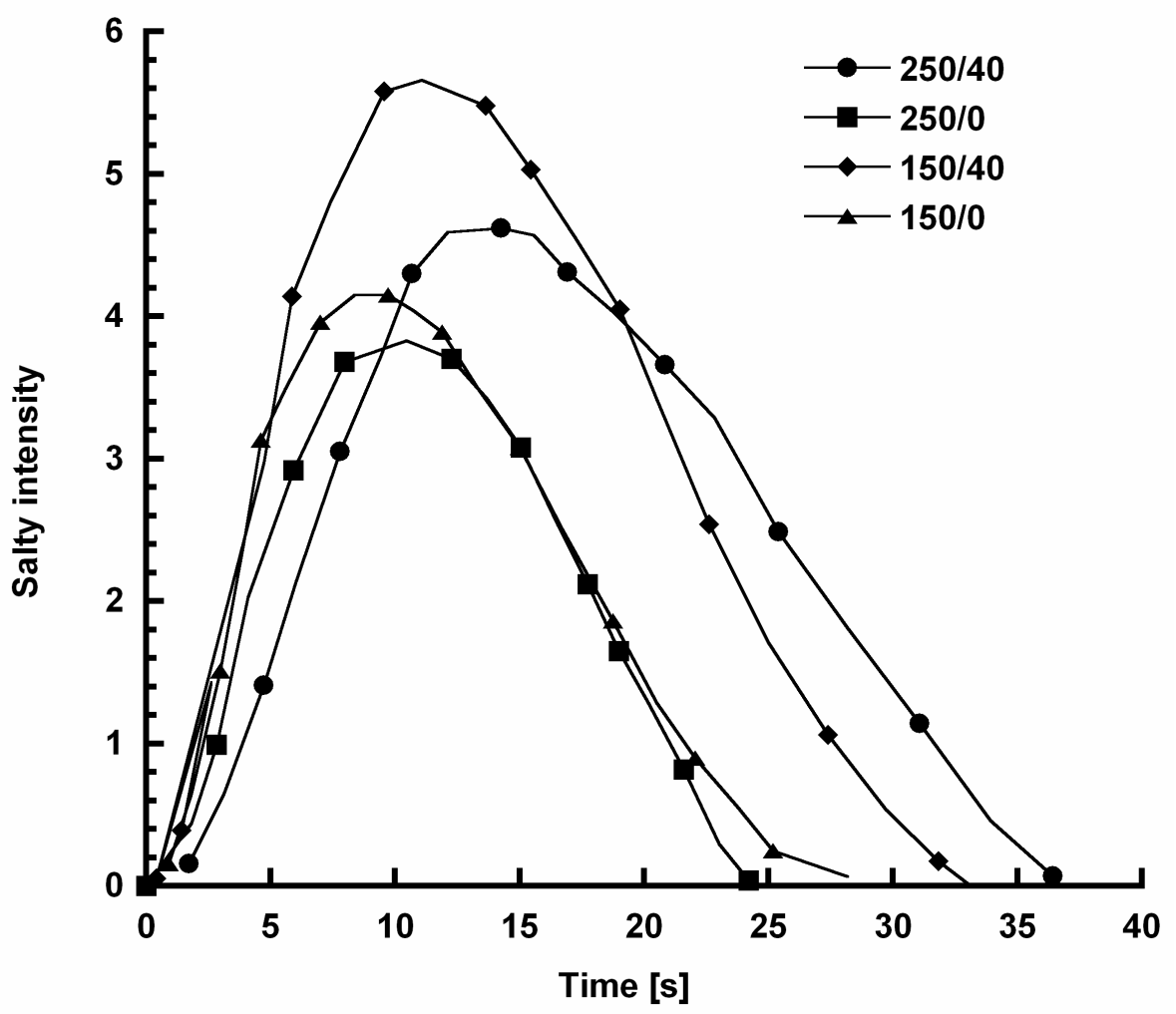

Figure 3: Mean of the time-intensity profiles for the four dairy gels. 


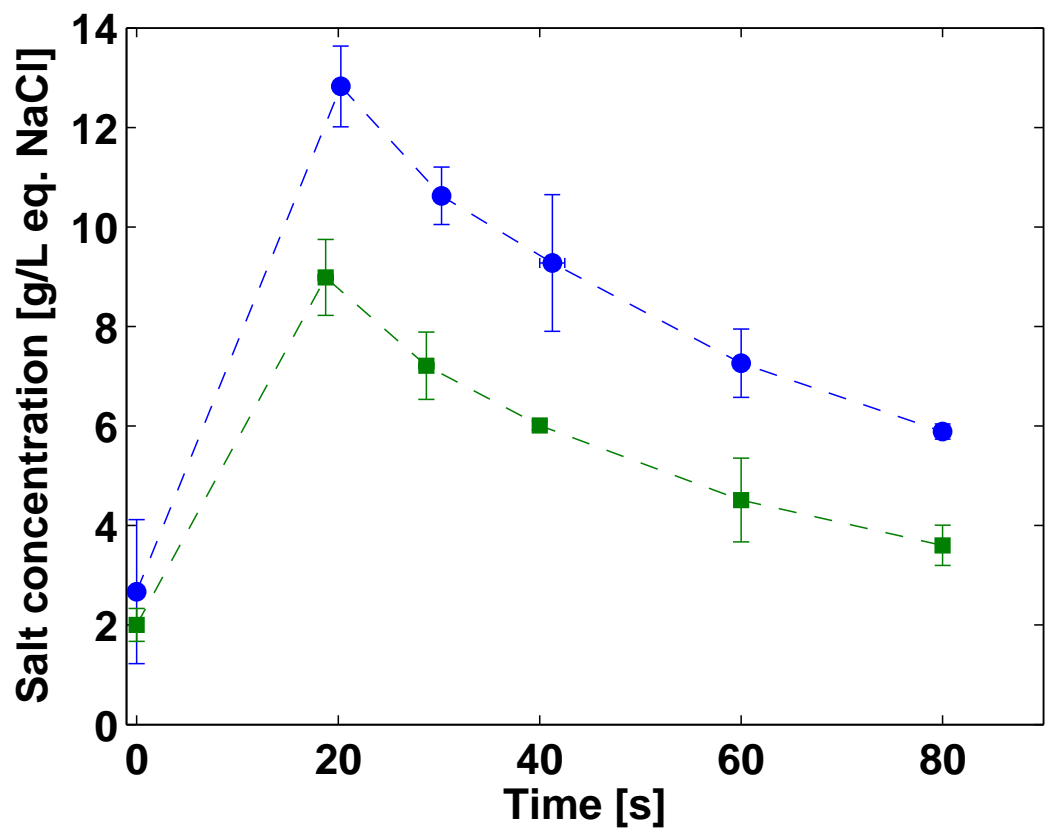

Figure 4: Examples of experimental release kinetics of salt in saliva for a panelist and

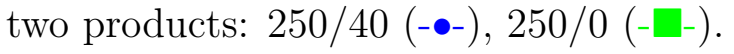




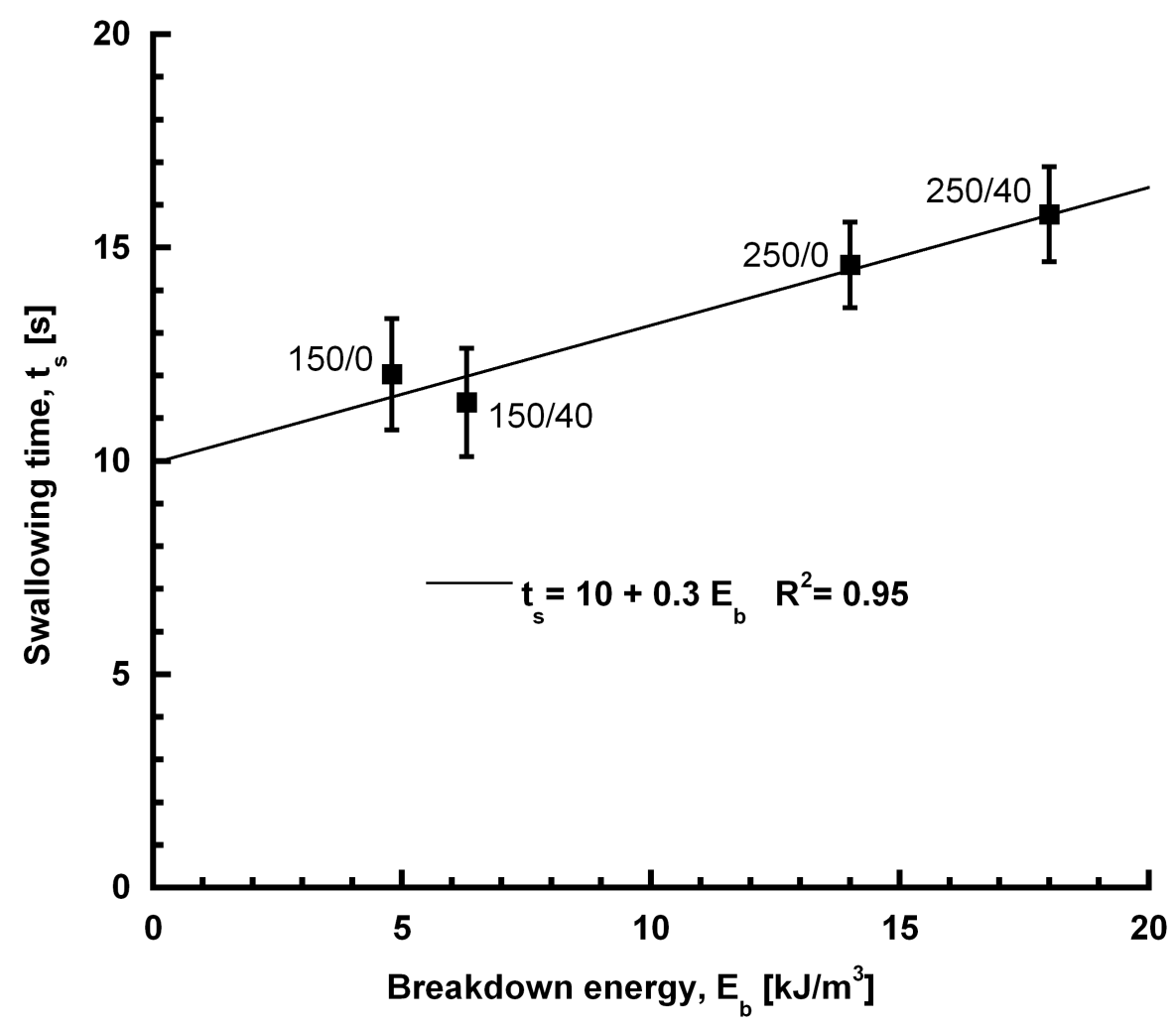

Figure 5: Mean swallowing time $t_{s}$ as a function of the breakdown energy $E_{b}$ for each product. Breakdown energy $E_{b}$ is defined as the energy necessary to break up the product at $80 \%$ of strain during a compression test (data calculated from the experiments carried out in (14)). Error bars represent confidence intervals. 

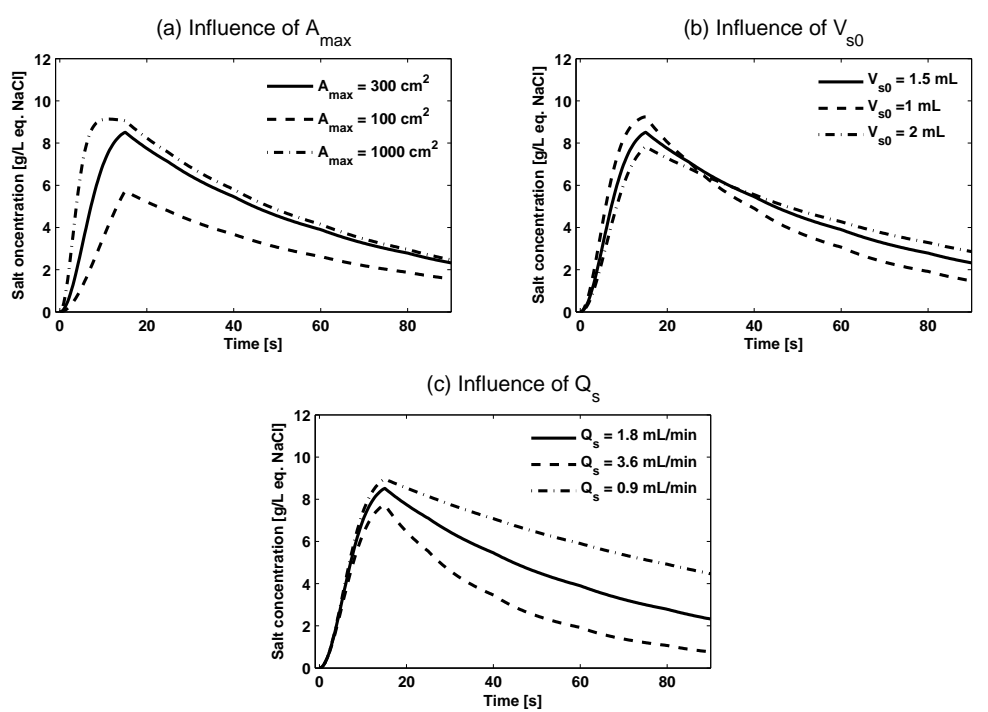

Figure 6: Parameter influence on model predictions: influence of the maximal contact area $A_{\max }$ (a); influence of the initial volume of saliva in the mouth $V_{s 0}$ (b); influence of the saliva flow rate $Q_{s}$ (c). The swallowing events take place at 15, 25, 40, 60 and $80 \mathrm{~s}$. Unless otherwise specified, parameter values are: $A_{\max }=100 \mathrm{~cm}^{2}, V_{s 0}=1 \mathrm{~mL}$ $Q_{s}=1.8 \mathrm{~mL} / \mathrm{min}, K=0.8, k_{p}=2.10^{-6} \mathrm{~m} / \mathrm{s}, V_{p}=5 \mathrm{~mL}$. 


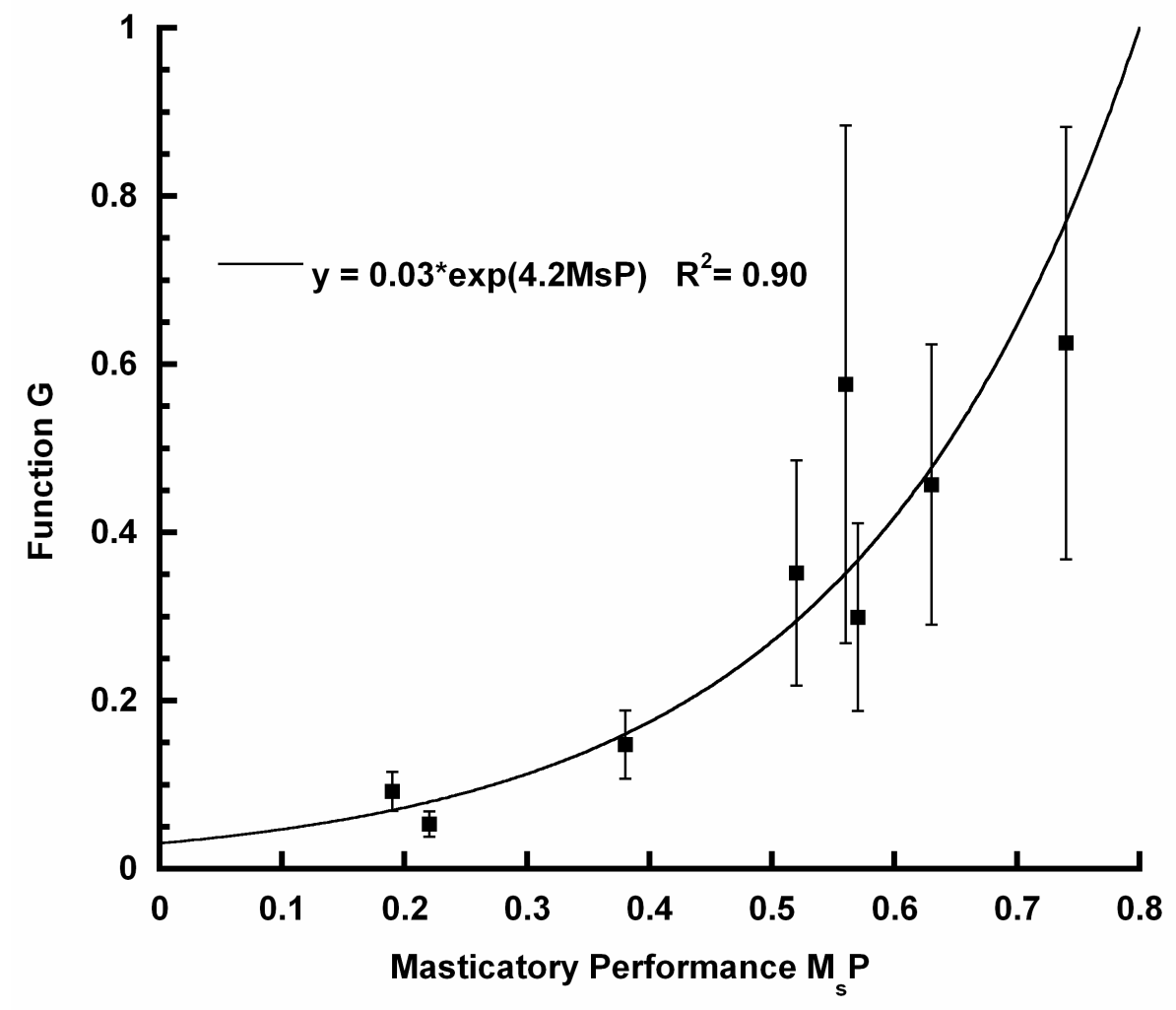

Figure 7: $G$ as a function of the masticatory performance. Each point represents a panelist. Error bars represent confidence intervals. 


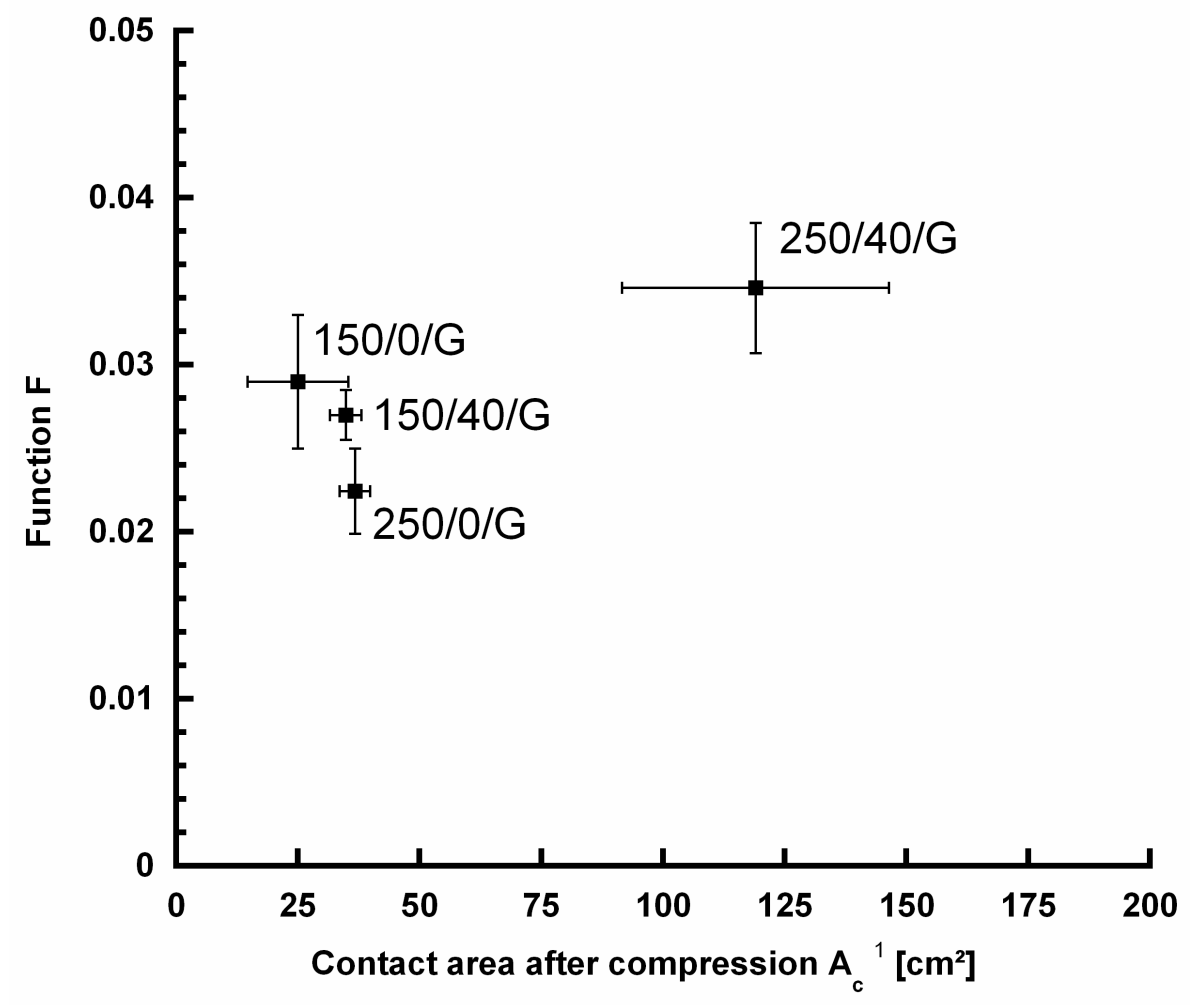

Figure 8: $F$ as a function of the contact area obtained after a standardised compression $A_{c}\left({ }^{1}\right.$ data from (13).). Error bars represent confidence intervals. 


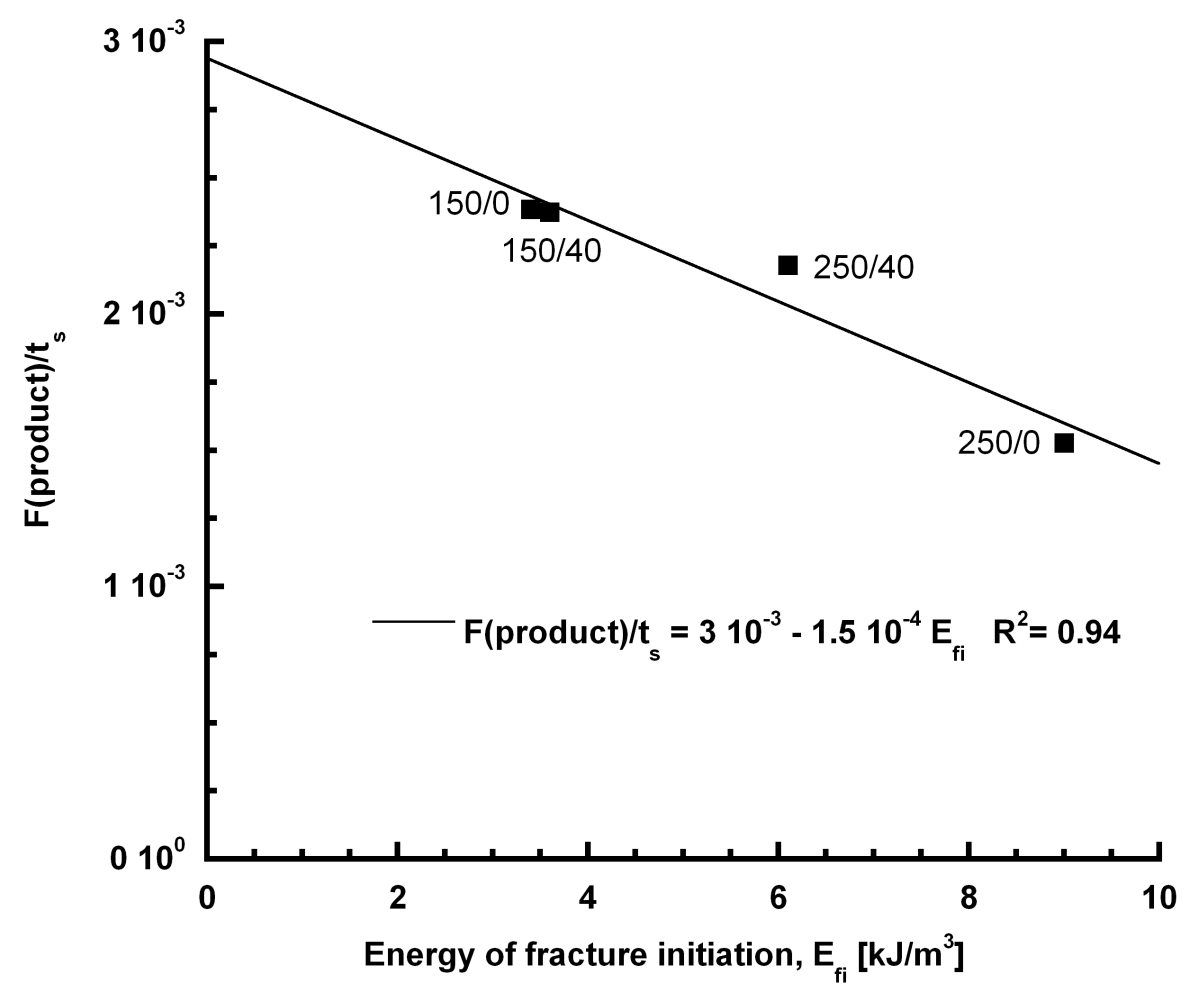

Figure 9: $F($ product $) / t_{s}$ as a function of the fracture initiation energy $E_{f i} . F($ product $) / t_{s}$ represents the dynamics of evolution of the contact area between the product and the saliva independently of the panelist effect. Fracture initiation energy $E_{f i}$ is defined as being the energy necessary to initiate the fracture in the product during a compression test (data calculated from the experiments carried out in (14)). 

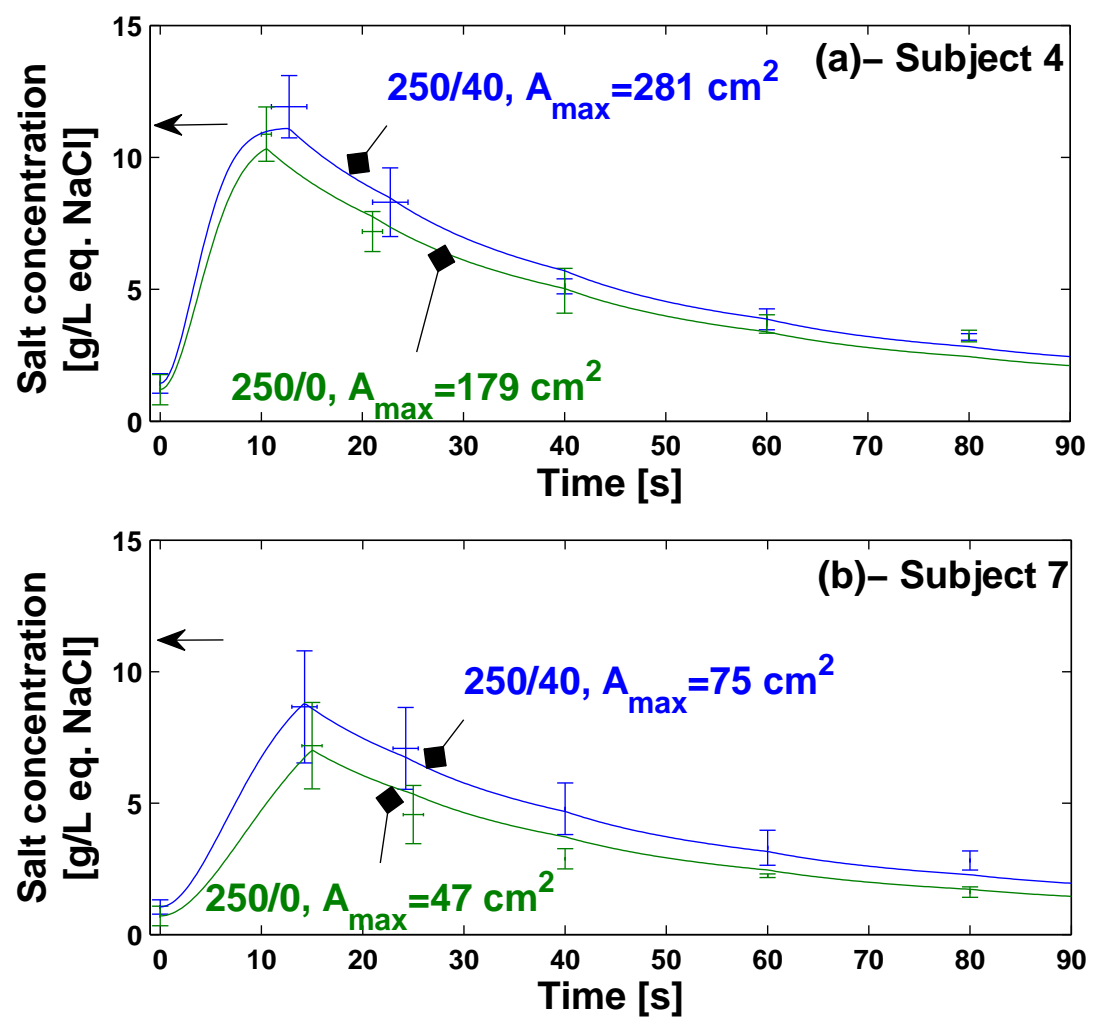

Figure 10: Experimental data and model of solutes release for two panelists with different masticatory performances $(M s P=0.52$ (a), $M s P=0.17(\mathrm{~b}))$ and two products $(250 / 40$ and 250/0). Arrows indicate the equilibrium salt concentration in saliva at the first swallowing event. 